\title{
Autopercepção da saúde bucal e impacto na qualidade de vida do idoso: uma abordagem quanti-qualitativa
}

\author{
Self-perception of oral health and impact on quality of life \\ among the elderly: a quantitative-qualitative approach
}

Desirée Sant'Ana Haikal ${ }^{1}$

Alfredo Maurício Batista de Paula ${ }^{1}$

Andrea Maria Eleutério de Barros Lima Martins ${ }^{1}$

Allyson Nogueira Moreira ${ }^{2}$

Efigênia Ferreira e Ferreira ${ }^{2}$

${ }^{1}$ Departamento de Odontologia, Centro de Ciências da Saúde (CCBS), Universidade Estadual de Montes Claros. Avenida Dr. Rui Braga s $/ n^{\circ}$. Caixa Postal 126, Vila Mauricéia. 39.401-089 Montes Claros MG.

desireehaikal@gmail.com ${ }^{2}$ Universidade Federal de Minas Gerais.

\begin{abstract}
A qualitative-quantitative approach was used in this study to obtain a clearer understanding of the relationship between self-perception, impact on quality of life and oral health among the elderly. Clinical examination and recorded interviews with objective and discursive questions were conducted with 45 institutionalized elderly people. Descriptive analyses of quantitative data were made. The interviews were transcribed and a systematic reading of the interviews was carried out selecting the components related to the categories under analysis. Photographic images of the oral clinical status were correlated with participants' speech. Quantitative analysis revealed: an average of 4.8 teeth; DMFT were 29.9; $57.7 \%$ were toothless; $60 \%$ believed they did not need dental care; $75 \%$ suffered a great impact on quality of life due to oral health conditions, despite the fact that $67 \%$ evaluated their oral health positively. Underestimation of symptoms, lack of hope and resignation due to limitations regarding poor clinical status were detected. Most elderly people viewed such limitations as a consequence of aging and not as a problem that may be solved. This reality can be changed through information and guidance for elderly people.
\end{abstract}

Key words Self-perception, Oral health, Quality of life, Aged, Qualitative research
Resumo Este estudo, de abordagem quanti-qualitativa, objetivou aprofundar o entendimento das relações entre autopercepção, impacto na qualidade de vida e condições bucais de idosos. Exame clinico e entrevista gravada contendo questões objetivas e discursivas foram realizados com 45 idosos. Conduziu-se análise descritiva quantitativa das questões objetivas e referentes ao exame clinico e à análise de conteúdo das questões discursivas de abordagem qualitativa. Imagens fotográficas do estado bucal foram relacionadas a trechos das entrevistas. A análise quantitativa evidenciou: 4,8 dentes em média; CPOD (número de dentes cariados, perdidos e obturados) médio de 29,9; 57,7\% eram desdentados, $60 \%$ acreditavam não necessitar tratamento, $75 \%$ sofriam impacto na qualidade de vida devido às condições bucais, apesar de 67\% perceberem positivamente sua saúde bucal. $\mathrm{Na}$ análise qualitativa constatou-se subestimação de sintomas, falta de esperança e resignação frente às limitações impostas pelo precário estado clínico. Muitos encararam as limitações como conseqüencia do envelhecimento e não como problema que mereça ser corrigido. O que mais incomodou foram as relações de dependência e a proximidade com a morte, minimizando outros problemas. A população idosa foi informada de que poderia modificar sua autopercepção, conscientizando-a que esta realidade pode ser modificada. Palavras-chave Autopercepção, Saúde bucal, Qualidade de vida, Idosos, Pesquisa qualitativa 


\section{Introdução}

A população idosa brasileira cresce rapidamente. O Brasil terá a sexta maior população idosa, em números absolutos, do mundo, chegando a aproximadamente $15 \%$ da população total em 2025 e a $19 \%$ em $2050^{1}$, enfatizando a necessidade de políticas de saúde públicas que enfoquem a manutenção de satisfatória qualidade de vida aos que envelhecem.

Problemas odontológicos podem influenciar a qualidade de vida e o bem-estar ${ }^{2}$. O Levantamento Epidemiológico das Condições de Saúde Bucal da População Brasileira, Projeto SB Brasil (2002/2003) realizado pelo Ministério da Saúde evidenciou um quadro crítico de saúde bucal para idosos: 54,8\% de desdentados totais, CPOD (número de dentes cariados, perdidos e obturados) médio de 27,93 e menos de $10 \%$ com mais de 20 dentes na boca ${ }^{3}$, proporção bem inferior à meta proposta pela Organização Mundial de Saúde (OMS) para o ano $2000^{4}$.

Dados epidemiológicos são fundamentais para planejamentos, organizações e monitoramentos dos serviços ${ }^{5}$, mas são restritos à visão profissional, objetiva. Ganham outro significado, quando acompanhados da avaliação da autopercepção das condições de saúde bucal, dada pelos próprios indivíduos, sobretudo considerando que o comportamento das pessoas é condicionado por suas percepções e pela importância dada a elas. Idosos foram apontados como maiores usuários de serviços médicos e maiores não usuários de serviços odontológicos. Mesmo em países que mantém programas odontológicos gratuitos dirigidos a idosos, a principal razão para não procurarem o serviço odontológico é a não percepção de sua necessidade ${ }^{6}$. Do ponto de vista prático, a autopercepção da saúde bucal tem impacto sobre a utilização dos serviços, sendo preditora de freqüência por procura de atendimento ${ }^{7-9}$.

Geralmente, pessoas idosas atribuem valores positivos à sua saúde bucal, mesmo com estados clínicos desfavoráveis ${ }^{8-17}$. Já as variáveis referentes ao impacto da saúde bucal na qualidade de vida, comumente aparecem associadas à autopercepção $0^{2,9,11,14,17}$, embora ainda seja necessário compreender melhor os elementos básicos que determinam esta autopercepção da saúde bucal.

Qualidade de vida é uma noção eminentemente humana, que tem sido aproximada ao grau de satisfação existencial, pressupondo uma síntese cultural dos elementos que determinada sociedade considera como padrão de conforto e bem-estar ${ }^{18}$. Neste sentido, na odontologia, in- dicadores sócio-odontológicos têm sido propostos para medir com que magnitude as alterações bucais comprometem a qualidade de vida e bemestar, e incluem medidas subjetivas como dor, incômodo, problemas estéticos, restrições na alimentação, na comunicação, nas relações afetivas, nas atividades diárias e no bem-estar psicológico dos indivíduos ${ }^{19}$. Destacam-se o Geriatric Oral Health Assessment Index (GOHAI) ou Índice de Determinação da Saúde Bucal Geriátrica, de Atchison e Dolan ${ }^{20}$, e o Oral Health Impact Profile (OHIP) ou Perfil do Impacto da Saúde Bucal, de Slade e Spencer ${ }^{21}$. Além destes, existem outros disponíveis na literatura científica cuja intenção acaba sendo quantificar o que é subjetivo, baseados em experiências de vida e mediados pelo contexto social, cultural e histórico vivenciados por cada indivíduo ${ }^{8}$.

O propósito deste estudo foi aprofundar o entendimento das relações entre autopercepção da saúde bucal, impacto da saúde bucal na qualidade de vida e estado clínico bucal de idosos.

\section{Metodologia}

$\mathrm{Na}$ busca de maior compreensão sobre as questões que permeiam os sentimentos e as representações quanto à saúde bucal de idosos e partindo da premissa de que a produção do conhecimento em saúde coletiva incorpora o social como um campo no qual a doença adquire um específico significado ${ }^{22}$, utilizou-se uma abordagem quanti-qualitativa. A forma puramente quantitativa seria limitada no entendimento do problema em questão, não dando conta de captar as experiências subjetivas dos indivíduos acerca de seu bem-estar. A pesquisa qualitativa apresenta relação dinâmica entre mundo objetivo e subjetividade do sujeito, que não pode ser traduzida em números. É voltada para a descoberta, identificação, descrição aprofundada e geração de explicações, além de buscar o significado e a intencionalidade dos atos ${ }^{23,24}$ contemplando o propósito deste trabalho.

Esta pesquisa foi previamente aprovada pelo Comitê de Ética em Pesquisas da Universidade Federal de Minas Gerais, atendendo à resolução 196/96 do Conselho Nacional de Saúde.

\section{População}

Uma das maiores instituições geriátricas de uma metrópole brasileira foi selecionada para compor o universo do estudo por possuir grande 
número de idosos residentes de diferentes classes sociais. Com o propósito de selecionar idosos com condições cognitivas para responder a entrevista, foi realizada a aplicação prévia do Mini-Exame do Estado Mental (MEM) ${ }^{25}$ por um psicólogo da instituição. Esse instrumento rastreia o comportamento cognitivo e tem sido empregado em estudos epidemiológicos ${ }^{26}$. A presente investigação refere-se aos 45 idosos que além de aceitarem participar da pesquisa, obtiveram pontuações superiores a 24 no MEM, não caracterizando possíveis quadros de demência ${ }^{26}$. Em pesquisas qualitativas, o tamanho da amostra não é o fator determinante, estando mais dependente da qualidade e profundidade das informações obtidas ${ }^{23}$. Entretanto, optou-se pelo recenseamento dos indivíduos que atenderam ao critério de capacidade cognitiva, superando o "ponto de saturação" normalmente utilizado em pesquisas qualitativas.

\section{Coleta de dados}

A coleta de dados foi realizada em dois momentos: entrevista e exame clínico bucal, a fim de que a entrevista não fosse influenciada pelo exame. Optou-se, entretanto, em apresentar inicialmente alguns resultados da entrevista e o estado clínico e em seguida os resultados qualitativos das entrevistas.

\section{Entrevistas}

A entrevista foi composta de uma parte estruturada, utilizando formulário em papel, e outra semi estruturada, de abordagem qualitativa, coletada com o auxílio de gravador de áudio. As variáveis investigadas de forma estruturada foram: idade (coletada como variável contínua e posteriormente categorizada por décadas); sexo (masculino; feminino); valor da contribuição mensal pago pelos idosos e/ou seus familiares à Instituição em reais ( 0 a 250; 350 a 500; 601 a 800; 801 a 1000; acima de 1000); necessidade percebida de ir ao dentista (sim; não) obtida pela pergunta "Você acha que está precisando ir ao dentista?" e autopercepção da saúde bucal (excelente; boa; regular; ruim; péssima) obtida pela pergunta "Como você acha que está a sua boca atualmente?". Foram considerados com autopercepção positiva aqueles que a classificaram como excelente ou boa; com autopercepção regular os que a classificaram como regular; e negativa os que a classificaram como ruim ou péssima.

Para a medida do impacto das condições bucais na qualidade de vida, optou-se por utilizar o
GOHAI $^{20}$ considerando suas dimensões: autopercepção de incômodos, de sintomatologia dolorosa no último ano, de problemas com a aparência, com a mastigação, com a fala e com limitações nas relações sociais, sendo cada dimensão coletada de forma dicotômica (presente; ausente).

A constatação, durante estudo piloto prévio, de que um instrumento quantitativo não seria adequado para esclarecer porque idosos autoperceberam positivamente sua saúde bucal, mesmo sofrendo impactos psicossociais, levou os pesquisadores a optarem pela abordagem qualitativa complementar, mantendo a coleta objetiva inicial. Foram então elaboradas questões discursivas relacionadas a costumes comuns em nossa cultura, inclusive entre idosos, tais como cantar, conversar, ser fotografado e se alimentar em locais públicos, buscando maior compreensão dos sentimentos gerados pelo estado clínico e como a saúde bucal pode impactar nas atividades cotidianas. As questões formuladas foram baseadas nas dimensões do GOHAI ${ }^{20}$, nas respostas registradas durante o primeiro estudo piloto e nas experiências dos pesquisadores (Quadro 1). Mais três estudos pilotos em outras instituições geriátricas foram realizados até as questões terem sido consideradas adequadas, cada um desses estudos contou com a participação de 10 idosos. Convém destacar que a noção de qualidade de vida adotada neste trabalho refere-se a padrões de satisfação, conforto e tolerância determinados pelos próprios sujeitos pesquisados, uma vez que tratam de valores socialmente determinados ${ }^{18}$.

A abordagem qualitativa requer estabelecimento de vínculo entre entrevistador e entrevistado, para que este se sinta à vontade no relato ${ }^{27}$. A pesquisadora responsável pelas entrevistas conviveu com os idosos por 30 dias, somente ausentando-se durante finais de semana e horário noturno. Após este período, iniciaram-se as entrevistas semi-estruturadas, aplicadas de forma flexível, permitindo intervenções ${ }^{27}$. Alguns temas surgiram espontaneamente e outros foram sistematicamente estimulados pela pesquisadora (Quadro 1). As gravações realizadas foram transcritas na íntegra.

\section{Exame clínico}

Todos os exames foram realizados por um único examinador treinado e calibrado que contou com a ajuda de um anotador, conforme critérios preconizados pela $\mathrm{OMS}^{5}$. Nesse estudo, foram considerados dados relativos ao CPOD e 
Quadro 1. Questões do $\mathrm{GOHAI}^{19}$ e questões utilizadas na presente investigação, segundo as dimensões avaliadas.

\begin{tabular}{|c|c|c|}
\hline $\begin{array}{l}\text { Dimensão } \\
\text { investigada }\end{array}$ & Questões GOHAI & $\begin{array}{c}\text { Questões utilizadas na presente } \\
\text { investigação }\end{array}$ \\
\hline Incômodo & $\begin{array}{l}\text { Sentiu-se nervoso ou tomou consciência } \\
\text { de problemas com seus dentes, gengivas } \\
\text { ou próteses? } \\
\text { Preocupou-se ou teve cuidados com seus } \\
\text { dentes, gengivas ou próteses? }\end{array}$ & $\begin{array}{l}\text { O que mais te incomoda em sua boca } \\
\text { atualmente? }\end{array}$ \\
\hline Dor & $\begin{array}{l}\text { Teve sensibilidade nos dentes ou gengivas } \\
\text { ao contato com calor, frio ou doces? } \\
\text { Usou medicamento para aliviar dor ou } \\
\text { desconforto relativos à boca? }\end{array}$ & $\begin{array}{l}\text { Você sentiu dor nos dentes ou } \\
\text { gengivas no último ano? Conte como } \\
\text { foi (em caso afirmativo) } \\
\text { Você precisou usar algum } \\
\text { medicamento para alivio de dor } \\
\text { relativa à boca no último ano? }\end{array}$ \\
\hline $\begin{array}{l}\text { Problemas } \\
\text { com a aparência }\end{array}$ & $\begin{array}{l}\text { Sentiu-se contente ou feliz com o aspecto } \\
\text { de seus dentes ou próteses? }\end{array}$ & $\begin{array}{l}\text { Se alguém tirar uma fotografia sua } \\
\text { você prefere aparecer sorrindo ou } \\
\text { sério? Por quê? }\end{array}$ \\
\hline $\begin{array}{l}\text { Dificuldade } \\
\text { mastigatória }\end{array}$ & $\begin{array}{l}\text { Foi capaz de engolir confortavelmente? } \\
\text { Limita o tipo ou a quantidade de } \\
\text { alimentos que come devido a problemas } \\
\text { com seus dentes ou próteses? } \\
\text { Tem problemas mastigando carne sólida } \\
\text { ou maçã? } \\
\text { Foi capaz de comer qualquer coisa sem } \\
\text { sentir desconforto? }\end{array}$ & $\begin{array}{l}\text { Como você costuma comer estes } \\
\text { alimentos? } \\
\text { Maçã inteira com casca, chupar } \\
\text { laranja, doces, carne em pedaços, } \\
\text { arroz e feijão, milho na espiga, pão, } \\
\text { salada de verdura crua, torrada, } \\
\text { sorvetes, torresmo. } \\
\text { Você tem dificuldade para comê-los? }\end{array}$ \\
\hline $\begin{array}{l}\text { Problemas com a } \\
\text { fonética }\end{array}$ & $\begin{array}{l}\text { Seus dentes ou próteses o impediram de } \\
\text { falar da maneira como queria? } \\
\text { Limitou seus contatos com outras pessoas } \\
\text { devido às condições de seus dentes ou } \\
\text { próteses? }\end{array}$ & $\begin{array}{l}\text { Você acha bom cantar? Tem alguma } \\
\text { coisa que te atrapalha cantar? O que? } \\
\text { Você conversa muito com outras } \\
\text { pessoas? Tem alguma coisa que }\end{array}$ \\
\hline $\begin{array}{l}\text { Limitação no } \\
\text { convívio social }\end{array}$ & $\begin{array}{l}\text { Sentiu desconforto ao alimentar-se em } \\
\text { frente a outras pessoas devido a problemas } \\
\text { com seus dentes ou próteses? }\end{array}$ & $\begin{array}{l}\text { Você teria algum problema em se } \\
\text { alimentar em um restaurante ou em } \\
\text { uma festa? Por quê? }\end{array}$ \\
\hline
\end{tabular}

a média do número de dentes presentes. Imagens fotográficas do estado clínico foram realizadas contribuindo de forma ilustrativa.

\section{Análise dos dados}

Foi realizada análise descritiva dos dados referentes ao estado clínico e à parte estruturada da entrevista. As falas transcritas das questões discursivas semi-estruturadas foram analisadas se- gundo a técnica de análise de conteúdo ${ }^{24}$ classificando os dados através de leituras repetidas das entrevistas e mergulho analítico profundo, produzindo interpretações e explicações que procuraram dar conta das questões que motivaram a investigação. Assim, fragmentos de entrevistas e imagens constituíram traços em torno dos quais foram realizadas reflexões ${ }^{23}$. Destaques em negrito nas falas foram realizados pelos autores a fim de evidenciar trechos que embasaram análises. 


\section{Resultados e discussão}

Dos 45 idosos avaliados, 35 (78\%) tinham mais de 71 anos e $27(60 \%)$ eram do sexo feminino. O valor mensal pago à instituição foi heterogêneo, variando de nenhuma contribuição até o máximo de $\mathrm{R} \$ 1.874,00$, confirmando coexistência de diferentes classes sociais. Verificou-se precário estado clínico: 4,8 dentes presentes em média; CPOD médio de 29,9 , com $92,8 \%$ de representatividade do componente perdido (extraídos- $91 \%$ e extração indicada-1,8\%); $26(57,7 \%)$ eram desdentados totais; somente 3 (7\%) idosos possuíam mais de 20 dentes presentes. Estes achados estão condizentes com os verificados entre idosos brasileiros, onde se tem observado a necessidade de tratamento em praticamente todos os indivíduos e a de reposições protéticas ${ }^{3,17,28-31}$. Apesar das necessidades acumuladas já identificadas na população desse estudo ${ }^{32}$, Vinte e sete (60\%) idosos não perceberam necessidade de tratamento odontológico, proporção essa superior à encontrada entre idosos participantes do SB Brasil $(45,6 \%)^{17}$. Vale comentar que neste estudo houve maior proporção de idosos mais velhos quando comparados aos idosos do SB Brasil, representados somente pela faixa etária de 65 a 74 anos $^{3,17,28,29}$.

Com relação às dimensões utilizadas para contabilizar impacto da saúde bucal na qualidade de vida observou-se a seguinte distribuição, em números absolutos e percentuais respectivamente: incômodos $(23 ; 51 \%)$, dor no último ano (13; $29 \%)$, problemas com a aparência $(6 ; 13 \%)$, dificuldade mastigatória $(17 ; 38 \%)$, problemas com a fala $(1 ; 2,2 \%)$ e limitação nas relações sociais (5; $11 \%)$. A proporção de acometimento verificada em cada dimensão foi inferior ao encontrados entre idosos do SB Brasil ${ }^{17}$, embora a aferição e as análises realizadas tenham sido diferentes. $\mathrm{Na}$ presente investigação, 34 (75\%) idosos foram afetados por pelo menos uma dimensão, condizente com o precário estado clínico bucal e contrastando com a autopercepção da saúde bucal.

A autopercepção da saúde bucal foi positiva para $30(67 \%)$, regular para $10(22 \%)$ e negativa para $5(11 \%)$ idosos. Este predomínio de autopercepção positiva já foi constatado em outras investigações ${ }^{9,11,14,15,17,29,33}$, e entre idosos da região sudeste, participantes do SB Brasil, a autopercepção da saúde bucal foi para 58,9\% positiva, $28,2 \%$ regular e $12,9 \%$ negativa ${ }^{29}$. A Tabela 1 sumariza as relações entre autopercepção positiva, regular e negativa e as variáveis investigadas. Entre aqueles com autopercepção negativa foi maior a proporção de idosos com 80 ou mais anos, de mulheres, e com menores valores pagos à instituição. Outros estudos não encontraram associação da autopercepção com a idade ${ }^{17}$ e o sexo $^{13,14,17,29,33,34}$. A associação da autopercepção com classe social ou renda foi verificada em alguns estudos ${ }^{14,29}$ e não em outros ${ }^{13,17}$. Nesse estudo, todos os idosos que autoperceberam negativamente sua saúde bucal e a maioria dos que autoperceberam como regular relataram a necessidade de ir ao dentista, indicando que a autopercepção em saúde bucal é preditora da procura por atendimento odontológico, conforme verificado em outras investigações ${ }^{6,17,28,29}$.

Estudos têm evidenciado diferenças entre as condições clínicas e a autopercepção do paciente ${ }^{8-14}$. Neste estudo, quanto menor o número médio de dentes presentes e maiores valores de CPOD médio, mais negativa foi a autopercepção da saúde bucal. Os idosos, em geral, apresentaram muitas perdas dentárias, gerando baixa prevalência de extrações indicadas. Entretanto, a proporção entre a média de dentes presentes e a média de elementos com extração indicada foi diferente entre os que autoperceberam positivamente e negativamente sua condição bucal. Entre idosos com autopercepção negativa parece haver poucos dentes presentes e em precário estado. $\mathrm{O}$ índice CPOD considera igual peso para todos os seus componentes, mas indivíduos conferem significados diferentes para cada componente ${ }^{9,14}$. Estudos conduzidos entre idosos brasileiros têm observado autopercepção mais positiva entre edentados do que entre dentados, possivelmente por manterem poucos dentes e em precárias condições ${ }^{17,29,33}$, já estudos internacionais, onde a média de dentes presentes é maior, observa-se associação inversa $a^{9,10,13,34}$.

Estudos ${ }^{8,9,11,14,17}$ têm demonstrado associação da autopercepção negativa em saúde bucal com variáveis relativas ao impacto da saúde bucal na qualidade de vida, especialmente nas dimensões de dor ${ }^{16,17,34}$, aparência ${ }^{9,17}$; problemas mastigató$\operatorname{rios}^{17}$ e limitação nas relações sociais ${ }^{11,17}$. Na presente investigação houve maior proporção de indivíduos relatando incômodos e problemas mastigatórios dentre os que autoperceberam negativamente sua condição bucal. Entretanto, pelo baixo poder estatístico da amostra, a verificação de relações quantitativas torna-se limitada.

A abordagem qualitativa evidenciou hipóteses explicativas para a autopercepção positiva da saúde bucal entre idosos que relataram impacto negativo da saúde bucal na qualidade de vida. 
Tabela 1. Distribuição da autopercepção da saúde bucal dos idosos investigados segundo variáveis sócio-demográficas, da autopercepção de necessidade de tratamento, do estado clínico, e referentes ao impacto da saúde bucal na qualidade de vida.

\begin{tabular}{|c|c|c|c|c|c|c|}
\hline Variáveis & n & $\%$ & $\mathbf{n}$ & $\%$ & $\mathbf{n}$ & $\%$ \\
\hline \multicolumn{7}{|l|}{ Idade $^{1}$} \\
\hline 61 a 70 anos & 07 & 23,3 & 03 & 30 & 0 & 0 \\
\hline 71 a 80 anos & 13 & 43,3 & 05 & 50 & 01 & 20 \\
\hline 80 anos ou mais & 10 & 33,3 & 02 & 20 & 04 & 80 \\
\hline \multicolumn{7}{|l|}{ Sexo $^{1}$} \\
\hline Feminino & 18 & 60 & 05 & 50 & 04 & 80 \\
\hline Masculino & 12 & 40 & 05 & 50 & 01 & 20 \\
\hline \multicolumn{7}{|c|}{ Valor pago à instituição em reais ${ }^{\star 1}$} \\
\hline 0 a 250 & 07 & 23,3 & 01 & 10 & 02 & 40 \\
\hline 350 a 500 & 05 & 16,7 & 02 & 20 & 02 & 40 \\
\hline 601 a 800 & 07 & 23,3 & 04 & 40 & 01 & 20 \\
\hline 801 a 1000 & 07 & 23,3 & 01 & 10 & 0 & 0 \\
\hline acima de 1000 & 04 & 13,3 & 02 & 20 & 0 & 0 \\
\hline \multicolumn{7}{|c|}{ Necessidade percebida de ir ao dentista ${ }^{1}$} \\
\hline Presente & 07 & 23,3 & 06 & 60 & 05 & 100 \\
\hline Ausente & 23 & 76,7 & 04 & 40 & 0 & 0 \\
\hline $\mathrm{CPO}-\mathrm{D}^{2}$ & \multicolumn{2}{|c|}{$28,8 \pm 4$} & \multicolumn{2}{|c|}{$29,8 \pm 3,6$} & \multicolumn{2}{|c|}{$31,0 \pm 1,7$} \\
\hline Dentes presentes ${ }^{2}$ & \multicolumn{2}{|c|}{$7,4 \pm 9,5$} & \multicolumn{2}{|c|}{$5,2 \pm 7,7$} & \multicolumn{2}{|c|}{$3,2 \pm 3$} \\
\hline Extração indicada por cárie ${ }^{2}$ & \multicolumn{2}{|c|}{$0,6 \pm 1,8$} & \multicolumn{2}{|c|}{$0,6 \pm 1,1$} & \multicolumn{2}{|c|}{$1,0 \pm 1,7$} \\
\hline \multicolumn{7}{|l|}{ Incômodos ${ }^{1}$} \\
\hline Presente & 13 & 43,3 & 05 & 50 & 05 & 100 \\
\hline Ausente & 17 & 56,7 & 05 & 50 & 0 & 0 \\
\hline \multicolumn{7}{|l|}{ Dor no último ano ${ }^{1}$} \\
\hline Presente & 09 & 30 & 02 & 20 & 02 & 40 \\
\hline Ausente & 21 & 70 & 08 & 80 & 03 & 60 \\
\hline \multicolumn{7}{|l|}{ Problemas com a aparência ${ }^{1}$} \\
\hline Presente & 05 & 16,7 & 01 & 10 & 0 & 0 \\
\hline Ausente & 25 & 83,3 & 09 & 90 & 05 & 100 \\
\hline \multicolumn{7}{|l|}{ Problemas mastigatórios ${ }^{1}$} \\
\hline Presente & 08 & 26,6 & 05 & 50 & 04 & 80 \\
\hline Ausente & 22 & 73,3 & 05 & 50 & 01 & 20 \\
\hline \multicolumn{7}{|l|}{ Problemas com a fonação ${ }^{1}$} \\
\hline Presente & 01 & 3,3 & 0 & 0 & 0 & 0 \\
\hline Ausente & 29 & 96,7 & 10 & 100 & 05 & 100 \\
\hline \multicolumn{7}{|l|}{ Limitação nas relações sociais ${ }^{1}$} \\
\hline Presente & 02 & 6,7 & 02 & 20 & 01 & 20 \\
\hline Ausente & 28 & 93,3 & 08 & 80 & 04 & 80 \\
\hline
\end{tabular}

"Salário mínimo corrente de R \$240,00 e 1U\$ equivalente a aproximadamente R 2,94 (dezembro/2003); ${ }^{1}$ Variável expressa em números absolutos (n) e porcentagens (\%); ${ }^{2}$ Variável expressa em médias e desvio padrão $( \pm$ ).

\section{Incômodos}

Dentre as dimensões relativas ao impacto, a presença de incômodos foi a mais prevalente (51\%). Foi importante a abrangência da questão "O que mais te incomoda em sua boca, atualmente?", dando liberdade para o idoso manifestar-se livremente. Foram mencionados nenhum incômodo, presença de desconfortos (queimação, dente quebrado, dente gasto, retenção de alimentos, gosto ou odor desagradável), dor, sangramento gengival, problemas estéticos, problemas mastigatórios, problemas com próteses, bem como menções sobre a necessidade de realizar algum tipo de tratamento odontológico. O relato abaixo foi obtido de um idoso que afirmou nenhum incômodo relativo à boca.

Tem uns dentes aqui, dá para mim comer. Falta uns, mas tá indo mais ou menos bem. Não tenho mau-hálito, não sinto dor, dá para falar. Os dentes 
que sobraram são tudo tratados, não tem nervo. (sexo masculino, 92 anos, nenhum incômodo percebido, autopercepção regular, Figura 1)

Apesar das precárias condições clínicas, com a presença de fístula, perdas dentárias e acentuado acúmulo de cálculo, o fato de não perceber limitação funcional parece ser determinante para o idoso mencionado não sentir-se incomodado, embora perceba que sua situação não está boa. Parece haver resignação diante das precárias condições bucais, possivelmente por desconhecimentos ou falta de esperança de que sua situação clínica pudesse ser melhorada. Resignado é aquele que "sofre com resignação, que não lamenta a sua sorte", com "submissão paciente aos sofrimentos”35. Os idosos de hoje são de uma época em que o edentulismo era praticamente inevitável aos mais velhos ${ }^{14,31}$. Essa concepção pode influenciar a percepção dos idosos avaliados como privilegiados por possuir dentes "tratados", independentemente do estado clínico em que se encontrem. O mesmo ocorreu quanto à presença de prótese.

A dentadura está bamba, mas não tem importância não, melhor que nada. (sexo feminino, 76 anos, autopercepção positiva, Figura 2)

Apesar de todos os idosos com autopercepção negativa terem relatado incômodos, a presença de incômodos não foi decisiva para uma avaliação negativa ou regular da saúde bucal. Dentre os 23 idosos que relataram incômodos, 13 autoperceberam positivamente sua saúde bucal. O relato abaixo revela essa situação.

No geral a boca está boa, tem só um único dente que me preocupa. É o único que tenho na boca. O resto está tudo bem. [...] A falta dos dentes me inco-

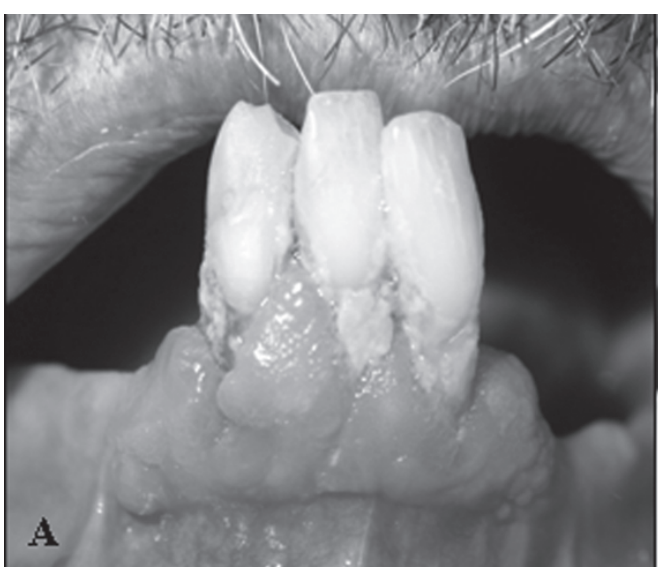

Figura 1. Estado clínico da cavidade bucal de idoso com 92 anos. moda porque sei que com isso incomodo outras pessoas porque demoro, preciso que corte muito pequeno. Meu sonho é ter um liquidificador pessoal para bater tudo. Eu não consigo engolir se não mastigar bem, mas não vou ficar amolando ninguém por causa disso... (sexo masculino, 72 anos, relato de incômodo, autopercepção positiva)

O idoso mencionado possuía alto poder aquisitivo, curso superior e convênio de assistência odontológica privada. Apesar de usar próteses em precárias condições, não autopercebeu necessidade de tratamento odontológico, sugerindo que o custo pode não ser a principal barreira para o uso do serviço odontológico, conforme apontado em outro estudo ${ }^{36}$. Este relato também explicita hipótese anteriormente levantada, de que a ausência de dentes é percebida mais positivamente do que a presença de poucos dentes em precárias condições. Além disso, o idoso sentia-se incomodado com a mastigação, mas não pelos seus próprios prejuízos, e sim por pensar incomodar outras pessoas, sugerindo que por isso autopercebeu positivamente sua saúde bucal. Se ele pudesse por si triturar os alimentos, possivelmente não relataria incômodo algum. A fala enfatiza a questão da dependência e da perda de autonomia, como impactantes na vida do idoso. Este outro relato também evidencia o problema, inclusive para ir ao dentista.

Precisar preciso (ir ao dentista), mas é difícil, estou esperando para ver se minha sobrinha me leva. Para mim tudo é difícil, minha sobrinha custa vir aqui ... o consultório dela está cheio, não pode ficar parando para vir aqui... (sexo feminino, 88 anos, autopercepção negativa, tia de dentista)

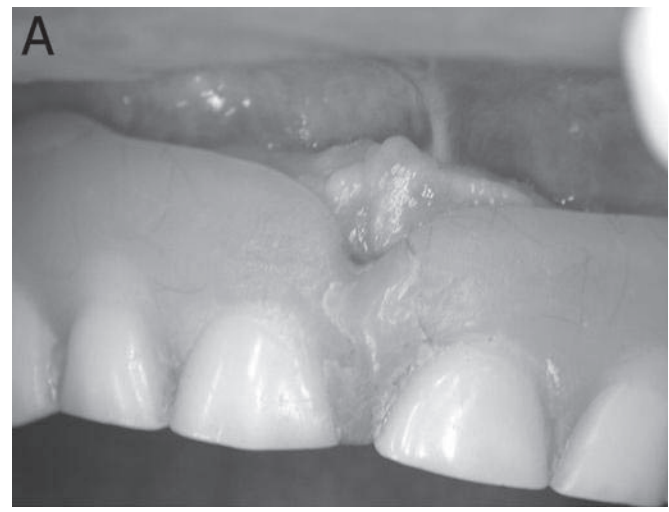

Figura 2. Estado clínico da cavidade bucal e da prótese utilizada por idosa com 76 anos. 


\section{Dor}

Dos 13 idosos que relataram dor, 9 autoperceberam positivamente suas condições bucais. Outras investigações evidenciaram associação direta entre sensibilidade dolorosa e autopercepção negativa ${ }^{17}$ e autopercepção da necessidade de tratamento ${ }^{7,28}$. Nesse estudo, nem a presença de dor foi relacionada a uma autopercepção da saúde bucal mais crítica, sugerindo percepção do envelhecimento desvinculado de qualidade de vida. Alguns idosos pareceram subestimar a sintomatologia dolorosa, aceitando-as como naturais da idade avançada, conforme relatos obtidos de idosos que tiveram autopercepção positiva.

A dentadura fere a gengiva e aí dói, mas é coisa à toa, vem e passa. (sexo feminino, 76 anos, Figura 2)

Sempre tem uma coisinha aqui, outra coisiquinha ali. Ah! Estou com 84 anos, vou morrer assim mesmo. (sexo feminino, 84 anos)

Somente quando a dor foi relatada como muito intensa, a autopercepção foi regular ou negativa.

Muita dor, dói até o ouvido. (sexo feminino, 83 anos, autopercepção negativa)

\section{Aparência}

Com relação à aparência, 6 entrevistados relataram problemas; dentre esses, 5 autoperceberam positivamente a saúde bucal, sugerindo que perceber problemas com a aparência também não determina autopercepção negativa da saúde bucal. Entretanto, outros idosos que não relataram objetivamente problemas com aparência, rela-

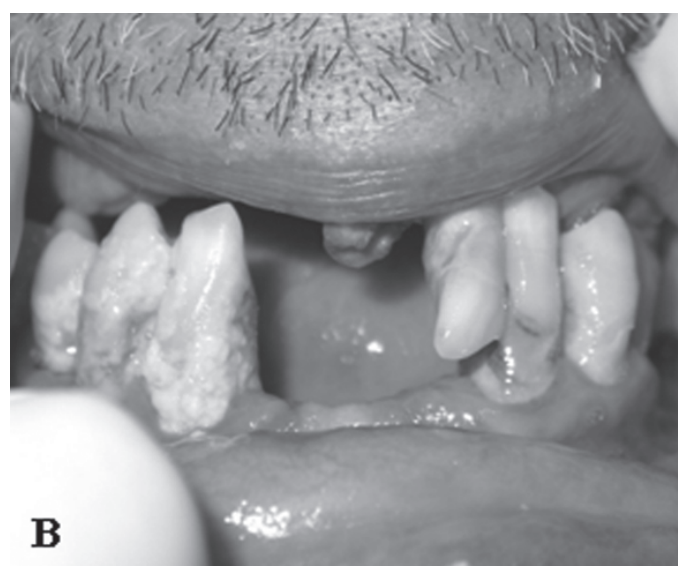

Figura 3. Estado clínico da cavidade bucal de idoso com 62 anos. ram, na abordagem qualitativa, insatisfações dessa natureza no ato de sorrir ao ser fotografado. A utilização de indicadores sócio-odontológicos de forma puramente quantitativa não capta esse tipo de situação. Dessa forma, é possível que o número de idosos que sofrem impactos na qualidade de vida devido à aparência da boca seja maior do que o usualmente captado. O relato abaixo retrata esse conflito.

Sei que toda pessoa deve tirar retrato sorrindo. Tenho frustração de não ter dentes, fico acanhado, mas venho trabalhando para superar isso. Tenho que me acostumar porque não vou ter dinheiro para arrumar, mas não vou deixar de sorrir por isso. (sexo masculino, 62 anos, autopercepção regular, Figura 3)

A falta de esperança em obter acesso aos serviços odontológicos, evidenciada na fala acima, gerou no idoso uma auto-imposição de conformação diante dos problemas bucais. Se o idoso em questão permanecesse sem tratamento, possivelmente passaria a ter uma autopercepção positiva, pois, atingiria com o tempo a aceitação pretendida, parando de combater aquilo que não acredita ter poder para mudar. Conformado é "aquele que se acomoda com infortúnios, desconfortos, desgraças" ${ }^{35}$, trazendo consigo a percepção de uma situação indesejável. Já a aceitação refere-se ao "fato de aceitar-se com naturalidade e conformação qualquer sofrimento ou infortúnio" ${ }^{35}$ passando a percepção de condição indesejável para condição predominantemente natural. A conformação e a aceitação parecem contribuir com o predomínio de autopercepção positiva diante de precárias condições clínicas, conforme revelado na fala abaixo, de uma idosa mais velha e já mais conformada.

Os dentes da frente ainda estão aí, embora enegrecidos, velhos, né? Mas não vai aparecer na foto. Melhor sorrir mesmo com os dentes assim do que ficar com cara fechada, carrancuda. (sexo feminino, 78 anos)

\section{Mastigação}

Problemas relacionados à mastigação foram identificados por 28 idosos. Entretanto, durante a abordagem qualitativa, quando perguntado sobre o consumo de onze alimentos específicos (Quadro 1), somente 13 idosos relataram conseguir mastigar todos eles. Esta discrepância foi causada pelo consumo de alimentos de maneira alternativa. Idosos com deficiências mastigatórias criam mecanismos alternativos para ingerir alimentos que não conseguiriam mastigar de for- 
ma convencional, adaptando-se tanto a elas, que deixam de representar algo problemático. Para muitos, amolecer, picar ou amassar os alimentos representa algo normal, que impede a percepção da dificuldade mastigatória. A abordagem qualitativa foi eficiente em captar este tipo de consumo, pois o número de indivíduos acometidos por problemas mastigatórios mais que dobrou. Abordagens puramente quantitativas não captam esse tipo de situação.

Como sem problemas. Amoleço no feijão primeiro, depois eu chupo. Se ainda ficar uns pedacinhos duro, eu engulo inteiro mesmo. (sexo masculino, 83 anos, sobre consumo de torresmo)

Vou te contar, tem alimento duro que a gente deixa na boca um pouco e ele amolece rápido. Torrada, biscoito. (sexo feminino, 75 anos)

Os idosos que perceberam objetivamente uma dificuldade mastigatória pareceram se referir mais à impossibilidade de ingerir alguns alimentos. Mesmo diante dessa limitação percebida, observa-se conformação e aceitação.

Alimentos duros, não dá. Todas as pessoas que usam dentadura têm esse problema, é normal. A gente vai se acostumando e procura comer sempre alimentos mais macios.... Tem coisa que não tem jeito. Côco e amendoim não dá, mas é tão fácil substituir. (sexo feminino, 75 anos)

Portanto, embora muitos idosos tenham problemas mastigatórios, percebe-se que a maioria não se importa, pois criou um mecanismo compensatório ao qual já se adaptou. Além disso, no geral, as deficiências mastigatórias não determinaram um impedimento ou limitação no convívio social.

Não teria problema algum (em se alimentar em um restaurante). Pediria um prato de acordo. Quem usa prótese tem que saber o que escolher, o que pode comer. Tem tanta coisa boa que a gente pode comer, por que insistir em coisa difícil. (sexo masculino, 75 anos, autopercepção positiva )

\section{Fonação e convívio social}

Um único indivíduo percebeu problemas com a fala e cinco perceberam limitação nas relações sociais na abordagem objetiva. Entretanto, mais uma vez, outros idosos mencionaram as condições odontológicas durante a avaliação qualitativa de questões sobre os atos de cantar, conversar ou se alimentar em público. Essas situações também não são captadas na utilização de indicadores sócio-odontológicos puramente quantitativos.

Tendo os dentes fica mais fácil cantar. Sem eles o som sai um pouco diferente, mas eu canto mesmo assim. (sexo masculino, 80 anos)
Eu mastigo só com estes dois dentes aqui, muita coisa eu engulo inteiro. Mas, nem ligo se os outros olham. (sexo feminino, 85 anos, sobre se alimentar em festas)

A baixa prevalência de indivíduos relatando problemas com a fala e nas relações sociais, assim como com a aparência, pode ser devida a sentimentos de solidão e abandono, conforme relato a baixo.

Quase não converso, aqui não tem ninguém para conversar... Detesto solidão. (sexo feminino, 88 anos)

\section{Autopercepção}

Os achados concernentes às questões qualitativas do impacto das condições bucais na qualidade de vida ajudam a compreender o predomínio de autopercepção positiva da saúde bucal, apesar do estado clínico precário. Abaixo, relatos apresentando algumas justificativas dadas pelos idosos ao autoperceberem positivamente suas condições bucais.

Não tenho nada não, falta fazer umas coisas que quebraram, mas pela minha idade, tá até bom. Tenho 69 anos e tá bom até demais. (sexo masculino, 69 anos)

A boca tá boa, em cima tenho dentadura, em baixo tem umas raízes que precisa arrancar, mas não quero arrancar agora porque não incomoda. (sexo feminino, 89 anos, Figura 4)

Em baixo tem alguns dentes, em cima não tem nada. Ah! Já estou no fim, não preciso de dentadura, nem de dentista. Não dói, dá pra continuar assim é só não mastigar coisa dura. (sexo feminino, 91 anos, autopercepção positiva, Figura 5)

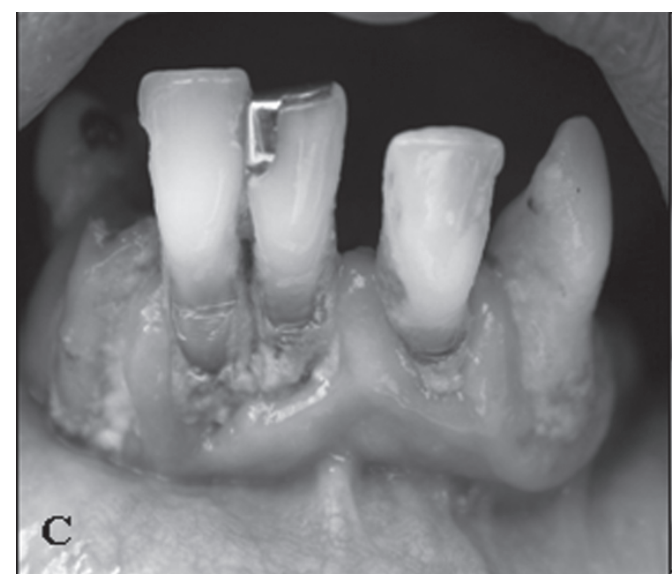

Figura 4. Estado clínico da cavidade bucal de idosa com 89 anos. 
Embora os idosos tenham identificado algumas condições clínicas ou necessidades de tratamento odontológico, eles não se referiram a elas como algo que deva ser melhorado ou resolvido, sugerindo baixa auto-estima e aceitação de limitações relacionadas à saúde bucal como naturais nesta fase da vida. Acredita-se que os idosos se tornam mais tolerantes com os problemas da cavidade bucal que surgem ao longo da velhice ${ }^{33}$. É responsabilidade de todo profissional de saúde orientar que doenças bucais, desconfortos e desfiguramentos não são conseqüências inevitáveis do envelhecimento ${ }^{14,37}$, mas decorrentes da instalação de processos patológicos que devem ser identificados e trabalhados de forma participativa e efetiva ${ }^{38}$. A educação em saúde desponta como um elo entre os desejos e expectativas dessa população por uma vida melhor e as projeções e estimativas dos governantes ao oferecer programas de saúde mais eficientes ${ }^{38}$.

Muitos idosos e seus familiares acreditam ainda que só devam procurar por atendimento odontológico em caso de dor. Mas muitas alterações odontológicas são assintomáticas e desconhecidas pelos indivíduos ${ }^{11}$ ou equivocadamente vistas como inevitáveis ao envelhecimento ${ }^{14}$. A baixa expectativa dos idosos em relação ao tratamento odontológico, e o fato de acreditarem que a visita ao dentista seja importante apenas para quem possui dentes, também representa importante barreira ao uso de serviços odontológicos ${ }^{28,39}$. Esses fatores parecem contribuir na baixa proporção $(40 \%)$ de idosos que perceberam a necessidade de ir ao dentista.

Dentista? Pra quê? Já não tenho dentes mais. Não tem nem porque ir agora. (sexo feminino, 88 anos, autopercepção positiva)

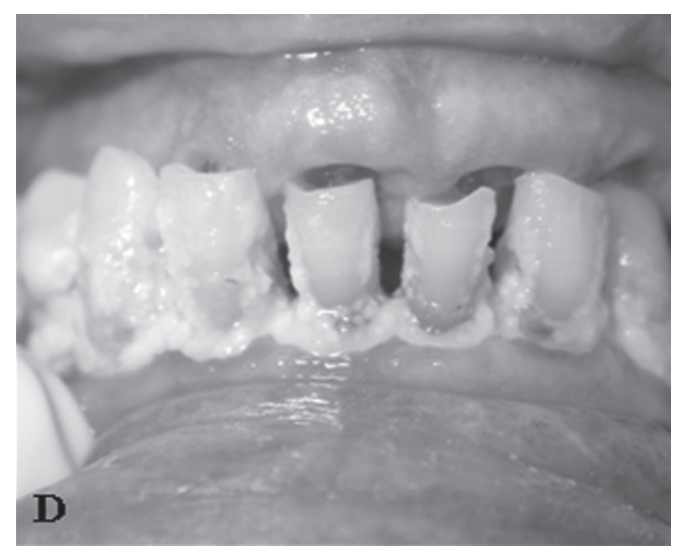

Figura 5. Estado clínico da cavidade bucal de idosa com 91 anos.
Conforme observado entre idosos do SB Brasil, indivíduos desdentados totais apresentaram menor percepção da necessidade de tratamento odontológico, apesar da utilização dos serviços por esses indivíduos ser necessária para avaliação de próteses e reconhecimento de alterações em tecidos moles, importantes no diagnóstico precoce do câncer de boca ${ }^{17,28}$.

Pessoas procuram ajuda quando realmente acreditam que esta lhes será disponível ${ }^{6}$. A falta de esperança em obter acesso a tratamento odontológico, por questões financeiras ou outras dificuldades, parece ser decisiva entre os que afirmaram não necessitar ir ao dentista. Muitos relatos evidenciam percepção de necessidades de tratamento, mas devido às dificuldades vivenciadas, muitos deixam de acreditar que isso seja possível.

Falta dinheiro para ir no dentista, está acabando de arrebentar os cacos todos. (sexo feminino, 83 anos)

Logo vou morrer. Não acho que vale a pena gastar com isso (dentista), tempo e dinheiro. Eu tenho pensado em outras coisas... Precisar, até que estaria precisando, não sei bem. Ah! Deixa pra lá. Não quero mexer com isso mais não. (sexo masculino, 70 anos, autopercepção positiva, Figura 6)

A conformação e a falta de esperança são elementos presentes na grande maioria dos espaços institucionais brasileiros ${ }^{40}$. De alguma forma estes indivíduos passam a ter valores sociais diferentes. A maioria, não parece se abater ou mesmo se indignar com precárias condições bucais e nem mesmo com as limitações conseqüentes destas condições. Os que gostam de cantar, conversar, sorrir, não vão deixar de fazer isso se tiverem à oportunidade, porque não têm dentes, ou porque a prótese balança. Eles se sentem inertes,

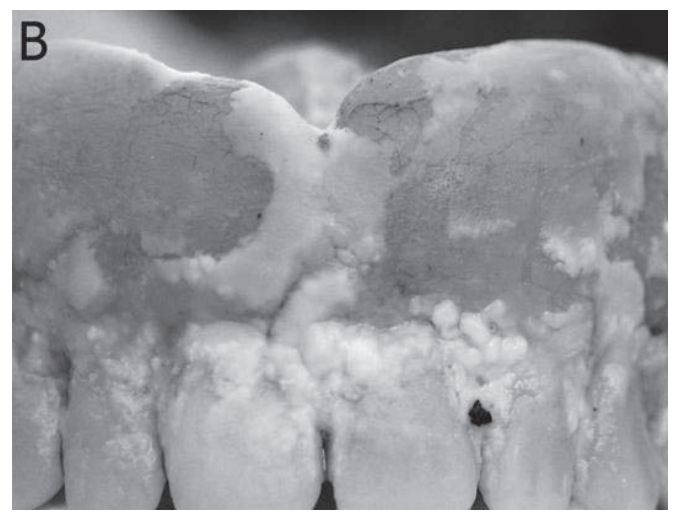

Figura 6. Estado da prótese utilizada por idoso com 70 anos. 
aguardando a morte e por isso aceitam a deteriorização de seu quadro de saúde bucal, não acreditando que mereçam, ou que seja possível possuírem melhores condições bucais. Quanto mais se enxergam deteriorados e com capacidades cada vez mais limitadas, mais se sentem próximos do fim e passam a enxergar a morte como algo tão próximo e certo, que permitem, muitas vezes, que seus corpos "morram" em vida. Há que se verificar se tais sentimentos são agravados pela institucionalização ou se acompanham o processo de envelhecimento per si, estando também presentes entre idosos não institucionalizados.

Daqui para a sepultura, vou ficar com esse dente mesmo. (sexo feminino, 89 anos)

Nesse estudo foram contabilizados somente os indivíduos que relataram objetivamente sofrer impactos em cada uma das dimensões avaliadas (Tabela 1), não levando em conta aqueles que, apesar de sofrerem limitações não as perceberam objetivamente. Portanto, apesar da alta porcentagem de idosos (75\%) sofrendo impactos das condições bucais na qualidade de vida, ainda assim, este dado está subestimado se forem consideradas as limitações reais, qualitativamente captadas, e não somente as percebidas, quantitativamente contabilizadas.

\section{Considerações finais}

O presente trabalho evidenciou que a maioria dos idosos autopercebeu positivamente sua saúde bucal, embora tenham apresentado precário estado clínico e sofram impacto negativo da saúde bucal na qualidade de vida.

Verificou-se alto CPOD, pequeno número médio de dentes presente e predomínio de idosos edentados totais. Apesar do estado precário dos poucos dentes presentes, a maioria afirmou não necessitar de tratamento odontológico.

A utilização da metodologia qualitativa foi efetiva em identificar fatores sociais que permitem melhor compreensão da autopercepção da saúde bucal entre idosos. Assim, constatou-se que os idosos perceberam alguns problemas ou a necessidade de tratamento, apesar da grande capacidade de aceitação das limitações impostas pelo precário estado clínico, com subestimação de sin- tomas, resignação com uma situação que tem como ser modificada e falta de esperanças de obterem acesso a tratamentos odontológicos. A maioria dos idosos encarou limitações como conseqüências inevitáveis do envelhecimento e não como um problema que mereça ou possa ser corrigido. Muitos idosos relataram que o precário estado clínico não os impede de vivenciar momentos importantes da vida social como a mastigação deficitária em ambientes públicos, o canto, a felicidade expressa pelo sorriso, até mesmo sem dentes. O que realmente incomodou e foi impactante na qualidade de suas vidas foram as relações de dependência, inclusive para ir ao dentista, a solidão e a proximidade com a morte, minimizando quaisquer outros problemas. A utilização de indicadores sócio-odontológicos quantitativos validados, como é o caso do GOHAI, tem a vantagem de permitir maior comparabilidade entre estudos, mas não captam essa subjetividade de sentimentos relacionados ao bem-estar e ao adoecer, nem crenças e valores pessoais atribuídos à saúde bucal, tão necessários para a compreensão do problema em questão.

A administração do atendimento odontológico ao idoso institucionalizado é complexa, mas essencial. No Brasil, o modelo de assistência geriátrica institucionalizada é, muitas vezes, de descaso, desrespeito e negligências. Mas é possível reverter esse quadro construindo condições sócio-culturais favoráveis a uma velhice bem sucedida, institucionalizada ou não. Se o idoso tiver vez e voz, poderá reiniciar um modo de vida interessante. Uma velhice consciente, atuante e disposta a intensificar seu presente com qualidade de vida. É este o desafio que temos pela frente.

\section{Colaboradores}

DS Haikal, AMB Paula, AMEBL Martins, AN Moreira e EF Ferreira participaram igualmente de todas as etapas da elaboração do artigo. 


\section{Referências}

1. Carvalho JAM, Rodríguez-Wong LL. A transição da estrutura etária da população brasileira na primeira metade do século XXI. Cad Saude Publica 2008; 24(3):597-605.

2. Locker D, Slade G. Association between clinical and subjective indicators of oral health status in an older adult population. Gerodontology 1994; 11(2): 108-114.

3. Brasil. Ministério da Saúde. Projeto SB BRASIL 2003: condições de saúde bucal da população brasileira 20022003: resultados principais. Brasília: Ministério da Saúde, Secretaria de Atenção à Saúde, Departamento de Atenção Básica; 2004.

4. FDI - Federation Dentaire Internationale. Global goals for oral health in the year 2000. Int Dental J 1982; 32(1):74-77.

5. World Health Organization. Oral Health surveys: basic methods. 4a ed. Geneva: ORH EPID; 1997.

6. Kiyak HA. Age and Culture: influences on oral health behavior. Int Dent J 1993; 43(1):9-16.

7. Gilbert GH, Heft MW, Duncan RP, Ringelberg M.L. Perceived need for dental care in dentate older adults. Int Dent J 1994; 44(2):145-152.

8. Gilbert L. Social factors and self-assessed oral health in South Africa. Community Dent Oral Epidemiol 1994; 22(1):47-51.

9. Matthias RE, Atchison KA, Lubben JE, De-Jong F, Schweitzer SO. Factors affecting self-ratings of oral health. J Public Health Dent 1995; 55(4):197-204.

10. Atchison KA, Mathias RE, Dolan TA, Lubben JE, Jong FD, Mayer-Oakes SA. Comparison of oral health ratings by dentists and dentate elders. J Public Health Den 1993; 53(4):223-230.

11. Jokovic A, Locker D. Dissatisfaction with oral health status in an older adult population. J Oral Health Dent 1997; 57(1):40-47.

12. Locker D. Clinical correlates of change in self perceived oral health in older adults. Community Dent Oral Epidemiol 1997; 25(3):199-203.

13. Gift HC, Atchison KA, Drury TF. Perceptions of the natural dentition in the context of multiple variables. J Dent Res 1998; 77(7):1529-1538.

14. Silva SRC, Fernandes RAC. Autopercepção das condições de saúde bucal por idosos. Rev Saúde Pública 2001; 35(4):349-355.

15. Silva DD, Sousa MLR, Wada RS. Autopercepção e condições de saúde bucal em uma população de idosos. Cad Saude Publica 2005; 21(4):1251-1259.

16. Nunes CIP, Abegg C. Factors associated with oral health perception in older Brazilians. Gerodontology 2008; 25(1):42-48.
17. Martins AMEBL, Barreto SM, Pordeus IA. Autoavaliação de saúde bucal em idosos: análise com base em modelo multidimensional. Cad Saude Publica 2009; 25(2):421-435.

18. Minayo MCS, Hartz ZMA, Buss PM. Qualidade de vida e saúde: um debate necessário. Cienc Saude Colet 2000; 5(1):7-18.

19. Chianca TK, Deus MR, Dourado AS, Leão AT, Vianna RBC. El impacto de la salud bucal en la calidad de vida. Rev Fola/Oral 1999; 5(16):96-102.

20. Atchison KA, Dolan TA. Development of geriatric oral health assessment index. Dental Educ 1990; 54(11): 680-687.

21. Slade GD, Spencer AJ. Social impact of oral conditions among older adults. Austr Dent J 1994; 39(6):358-364.

22. Botazzo C. Sobre a bucalidade: notas para a pesquisa e contribuição ao debate. Cienc Saude Colet 2006; 11(1):7-17.

23. Duarte R. Pesquisa qualitativa: reflexões sobre o trabalho de campo. Cad Pesqui 2002; (115):139-154.

24. Minayo MCS. O desafio do conhecimento: pesquisa qualitativa em saúde. $8^{\text {a }}$ ed. São Paulo: Hucitec/ Abrasco; 2004.

25. Folstein MF, Folstein SE, McHugh PR. - "Minimental state". A practical method for grading the cognitive state of patients for the clinician. J Psychiatr Res 1975; 12(3):189-198.

26. Brucki SMD, Nitrini R, Caramelli P, Bertolucci PHF, Okamoto IH. Sugestões para o uso do Mini-Exame do Estado Mental no Brasil. Arq Neuropsiquiatr 2003; 61(3-B):777-781.

27. Schraiber LB. Pesquisa qualitativa em saúde: reflexões metodológicas do relato oral e produção de narrativas em estudo sobre a profissão médica. Rev Saúde Pública 1995; 29(1):63-74.

28. Martins AMEBL, Barreto SM, Pordeus IM. Fatores relacionados à autopercepção da necessidade de tratamento odontológico entre idosos. Rev Saúde Pública 2008; 42(3):487-496.

29. Matos DL, Lima-Costa MF. Auto-avaliação da saúde bucal entre adultos e idosos residentes na Região Sudeste: resultados do Projeto SB-Brasil, 2003. Cad Saude Publica 2006; 22:1699-1707.

30. Colussi CF, Freitas SFT. Aspectos epidemiológicos da saúde bucal do idoso no Brasil. Cad Saude Publica 2002; 18(5):1313-1320.

31. Moreira RS, Nico LS, Tomita NE, Ruiz T. A saúde bucal do idoso brasileiro: revisão sistemática sobre o quadro epidemiológico e acesso aos serviços de saúde bucal. Cad Saude Publica 2005; 21(6):16651675. 
32. Haikal DS. Saúde bucal em um grupo de idosos institucionalizados: autopercepção, avaliação das condições observadas e impacto na qualidade de vida. [dissertação]. Belo Horizonte (MG): Faculdade de Odontologia, UFMG; 2004.

33. Bulgarelli AF.; Manço ARX. Idosos vivendo na comunidade e a satisfação com a própria saúde bucal. Cien Saude Colet 2008; 13(4):1165-1174.

34. Atchison KA, Gift HC. Perceived oral health in a diverse sample. Adv Dent Res 1997; 11(2):272-280.

35. Ferreira ABH. Novo Aurélio Século XXI: o dicionário da lingua portuguesa. $3^{\text {a }}$ ed. Rio de Janeiro: Nova Fronteira; 1999.

36. Matos DL, Lima-Costa MF, Guerra HL, Marcenes W. Projeto Bambuí: estudo de base populacional dos fatores associados com o uso regular de serviços odontológicos em adultos. Cad Saude Publica 2001; 17(3):661-668.

37. Dolan TA. Identification of appropriate outcomes for an aging population. Spec Care in Dentistry 1993; 13(1):35-39.

38. Melo MC, Souza AL, Leandro EL, Mauricio HÁ, Silva ID, Oliveira JMO. A educação em saúde como agente promotor de qualidade de vida para o idoso. Cien Saude Colet 2009; 14(Supl. 1):1579-1586.

39. Antczak AA, Branch LG. Perceived barriers to the use of dental services by the elderly. Gerodontics 1985; 1(4):194-198.

40. Vieira EB. Instituições Geriátricas: avanço ou retrocesso? Rio de Janeiro: Revinter; 2002.

Artigo apresentado em 23/08/2009

Aprovado em 25/09/2009

Versão final apresentada em 10/10/2009 